\title{
Chronic Marijuana Smoking Does Not Negatively Impact Select Blood Oxidative Stress Biomarkers in Young, Physically Active Men and Women
}

\author{
Richard J. Bloomer*, Matthew Butawan, Nicholas J. G. Smith \\ School of Health Studies, University of Memphis, Memphis, TN, USA \\ Email: *rbloomer@memphis.edu, mbbtawan@memphis.edu, njsmith3@memphis.edu
}

How to cite this paper: Bloomer, R.J., Butawan, M. and Smith, N.J.G. (2018) Chronic Marijuana Smoking Does Not Negatively Impact Select Blood Oxidative Stress Biomarkers in Young, Physically Active Men and Women. Health, 10, 960-970.

https://doi.org/10.4236/health.2018.107071

Received: June 19, 2018

Accepted: July 14, 2018

Published: July 17, 2018

Copyright $\odot 2018$ by authors and Scientific Research Publishing Inc. This work is licensed under the Creative Commons Attribution International License (CC BY 4.0).

http://creativecommons.org/licenses/by/4.0/ (c) (i) Open Access

\begin{abstract}
Background: The smoking of Cannabis sativa, the marijuana plant, is increasing in popularity among young adults, even those who may be engaged in regular exercise (i.e., athletes). Research has shown the plant to have antioxidant and analgesic properties, but the effects on oxidative stress are conflicting. The purpose of this study was to measure blood oxidative stress and cardio-metabolic parameters in physically active men and women who regularly smoke marijuana. Methods: A total of 43 marijuana smokers $(23 \pm 4$ years) and 22 non-smokers ( $24 \pm 7$ years), who did not smoke tobacco products, participated in this study. Both smokers and non-smokers engaged in regularly exercise, totaling several hours per week $(6.4 \pm 4.0$ and $6.8 \pm 4.4$, respectively). Smokers reported using marijuana frequently during the week ( 4.5 \pm 2.3 sessions) for a minimum of three consecutive months prior to participating in the study. Blood samples were collected from participants following a 12-hour fast (all food, drink [except water] and smoking) and analyzed for malondialdehyde, advanced oxidation protein products, glucose, cholesterol, and triglycerides. Heart rate and blood pressure was also measured and recorded. Results: No differences of statistical significance were noted for any variable $(p>0.05)$, with very similar values noted between smokers and non-smokers. Conclusions: In a sample of young, physically active men and women, regular marijuana smoking is not associated with untoward effects on select biomarkers of oxidative stress and cardio-metabolic health. These findings do not suggest that marijuana smoking can be done without harm, as limitations of this study need to be considered.
\end{abstract}

\section{Keywords}

Marijuana, Cannabis, Oxidative Stress, Lipid Peroxidation, Protein Oxidative 


\section{Background}

Despite its illegality in many parts of the United States (US), as well as in other countries around the world, marijuana smoking is popular among young adults [1]. Increasing concern exists that its use may increase as more states and countries legalize the recreational use of this plant [2]. Marijuana has been cited as the most commonly used illicit drug [3], with approximately $10 \%$ of the US population reporting its use [4]. While the smoking of marijuana was once thought to be limited to a certain segment of the population, recent trends indicate that people from all walks of life may partake in this activity-partly owing to the widespread accessibility of this plant [5] [6] and partly to the suggested medicinal qualities [7]. This includes athletes [8] and those involved in programs of regular physical activity [9], for which multiple health benefits are often realized [10] [11] [12].

One of the noted effects of regular physical exercise is an upregulation in endogenous antioxidant enzymes [13] [14] [15], such as superoxide dismutase, catalase, and glutathione peroxidase. This desirable outcome helps to combat reactive oxygen species (ROS) and minimize the oxidative stress that may occur in response to frequent and significant ROS production. Overproduction of ROS can lead to cell damage and unnecessary apoptosis [16] [17] and oxidative stress is commonly associated with cancer [18] [19], neurodegenerative disease [20] [21], cardiovascular diseases [22] [23], and diabetes [24]. A strong body of evidence links nicotine-containing cigarette smoke to elevated ROS production and oxidative stress [25] [26] [27]. However, despite the growing popularity of marijuana smoking, no current data exists characterizing the systemic oxidative stress status of regular marijuana smokers.

The marijuana plant, Cannabis sativa, contains more than 60 different compounds referred to as cannabinoids [28]. Interestingly, cannabinoids contain phenolic groups, such as cannabidiol and cannabinol, and are known to have antioxidant properties [29]. That said, it is known that marijuana smoke in vitro can stimulate ROS production [30], suggesting that chronic smoking of marijuana may lead to oxidative stress.

The present study sought to determine the degree of oxidative stress, as measured by lipid peroxidation and protein oxidation, in a sample of young, physically active marijuana smokers. We maintained a non-directional hypothesis for the following reasons: 1) Data indicate both an increase in ROS with marijuana smoke exposure, as well as an antioxidant potential of specific plant compounds; 2) exercise training and a subsequent upregulation in antioxidant enzyme activity could counteract the elevation in ROS owing to the marijuana smoking.

\section{Methods}

\subsection{Subjects and Screening}

Data from a total of 43 marijuana smokers and 22 non-smokers were used in this study. None of these 65 individuals reported smoking tobacco products. 
Due to the novelty of this work, subjects were not restricted based on body mass index or dietary intake. That said, individuals who were using certain medications (e.g., statins, anti-inflammatory, steroids) which are known to impact the outcome measures of the investigation were excluded. Subjects were recruited into the study through the use of flyers and online announcements. They discretely contacted the study coordinator and arranged a time to report to the lab. Since both smokers and non-smokers were included in this study, confidentiality regarding subjects' use of marijuana, which is currently illegal in the state of Tennessee, was not a concern. Health history, medication, and dietary supplement usage, and physical activity questionnaires were completed by all subjects. Both smokers and non-smokers were highly active and engaged in regular exercise, totaling several hours per week ( $6.4 \pm 4.0$ and $6.8 \pm 4.4$, respectively).

Subjects were accepted as a marijuana smoker if they had smoked marijuana at least one time per week for the previous three consecutive months. Analysis indicated that smokers used marijuana frequently during the week $(4.5 \pm 2.3$ sessions), although we were unable to verify this or to determine the potency of the plant. Women reported to the lab for their assessment during the first three days of their menstrual cycle, as hormonal fluctuations can influence the desired outcome measures.

Prior to participation, each subject was informed of all procedures, potential risks, and benefits associated with the study through verbal and/or written form in accordance with the procedures approved by the University Institutional Review Board for Human Subjects Research (Protocol \#4232). Subjects provided written informed consent prior to being admitted to participate, by using their unique subject ID number. Subject identity related to their health history and all data was maintained on a password protected computer. Subjects were compensated $\$ 20$ for their participation, payable in cash at the conclusion of their lab session, within a private office.

\subsection{Laboratory Visit}

Participants reported to the lab a single time in the morning hours following a 12-hour overnight fast (except for water). Participants also refrained from smoking marijuana during the 12 hours prior to the test visit. During this visit, they completed the informed consent form, health history, and physical activity questionnaires. Subjects' heart rate and blood pressure, height, weight, waist and hip circumference were measured. A blood sample (approximately $10 \mathrm{~mL}$ ) was drawn, the sample processed in a refrigerated centrifuge, and plasma obtained and stored in multiple aliquots at -70 degrees Celsius until analyzed.

Blood samples were assayed in duplicate. Triglyceride, cholesterol, and glucose were analyzed using an automated chemistry analyzer (Vet Axcel; Alfa Wasserman, West Caldwell, NJ). Reagents were supplied in manufacturer produced kits for triglyceride (SA1023; Alfa Wasserman, West Caldwell, NJ), cholesterol (SA1010; Alfa Wasserman, West Caldwell, NJ), and glucose (SA1014; 
Alfa Wasserman, West Caldwell, NJ). Malondiadehyde was analyzed using a commercially available colorimetric assay (NWK-MDA01; Northwest Life Science Specialties, Vancouver, WA), using similar methods as previously described [31]. Advanced Oxidation Protein Products were analyzed using a commercially available assay (STA-318 OxiSelect AOPP; Cell Biolabs, Inc., San Diego, CA) using the methods as previously described [32]. Both of these measures are widely used as indicators of lipid peroxidation and protein oxidation, respectively. That said, multiple other biomarkers of oxidative stress exist and our use of only these two measures may be considered a limitation of this work. Heart rate and blood pressure were measured in duplicate following a 10 minute period of seated rest, using an automated unit (HEM-907XL; Omron Healthcare, Hoofddorp, The Netherlands).

\subsection{Data Analysis}

Values for all variables were calculated and the data are presented as mean \pm SD. Comparisons between marijuana smokers and non-smokers were made using an analysis of variance. Statistical significance was considered at $\mathrm{p}<0.05$.

\section{Results}

A total of 69 subjects initially participated in this study and provided data. However, it was determined that four of these subjects were both marijuana and cigarette smokers and in order to maintain a more homogenous sample, we decided to exclude these individuals from the analysis. If the number of dual smokers vs. marijuana smokers vs. non-smokers was relatively similar, it may have been interesting to compare data between these three groups. However, with only four of the 69 subjects being marijuana and cigarette smokers, we felt it was appropriate to exclude these individuals. For the remaining 65 subjects, data were collected, analyzed, and presented in Table 1.

Outcome measures were very similar between smokers and non-smokers, with no differences of statistical significance noted for any variable ( $\mathrm{p}>0.05)$. $\mathrm{P}$ values for all variables, along with mean \pm SD values are presented in Table 1.

\section{Discussion}

We evaluated blood oxidative stress and cardio-metabolic parameters in young, physically active marijuana smokers. In those who regularly smoke marijuana but who also engage in frequent, moderate volume exercise, there is no elevation in either lipid peroxidation or protein oxidation as compared to non-smokers, nor is there any negative impact on cholesterol, triglycerides, glucose, or blood pressure. These data are specific to a sample of men and women who smoke marijuana an average of $4.5 \pm 2.3$ sessions per week for at least the three month period prior to participating in the study.

Prior research has documented the stimulating effect of marijuana smoke on ROS production [30] [33] [34]. Endothelial cells exposed to marijuana smoke in 
Table 1. Subject characteristics and blood borne variables for young, physically active marijuana smokers.

\begin{tabular}{|c|c|c|c|}
\hline Variable & $\begin{array}{l}\text { Smoker } \\
(\mathrm{n}=43)\end{array}$ & $\begin{array}{l}\text { Non-Smoker } \\
\quad(\mathrm{n}=22)\end{array}$ & P-value \\
\hline Age (years) & $22.6 \pm 3.9$ & $24.2 \pm 6.8$ & 0.21 \\
\hline Height $(\mathrm{cm})$ & $177.8 \pm 9.1$ & $178.0 \pm 7.2$ & 0.91 \\
\hline Weight (kg) & $80.0 \pm 15.7$ & $81.6 \pm 15.5$ & 0.77 \\
\hline BMI $\left(\mathrm{kg} \cdot \mathrm{m}^{-2}\right)$ & $25.3 \pm 4.9$ & $25.7 \pm 4.7$ & 0.74 \\
\hline Waist $(\mathrm{cm})$ & $85.1 \pm 20.5$ & $85.3 \pm 8.8$ & 0.96 \\
\hline Hip $(\mathrm{cm})$ & $105.3 \pm 20.3$ & $102.7 \pm 10.3$ & 0.55 \\
\hline Heart Rate (bpm) & $67.7 \pm 12.5$ & $70.2 \pm 15.3$ & 0.54 \\
\hline Systolic Blood Pressure (mm Hg) & $128.3 \pm 12.1$ & $126.4 \pm 9.9$ & 0.69 \\
\hline Diastolic Blood Pressure ( $\mathrm{mm} \mathrm{Hg}$ ) & $75.9 \pm 8.5$ & $72.4 \pm 8.6$ & 0.13 \\
\hline Anaerobic Exercise $\left(\mathrm{hr} \cdot \mathrm{wk}^{-1}\right)$ & $2.5 \pm 2.6$ & $2.8 \pm 4.2$ & 0.54 \\
\hline Aerobic Exercise $\left(\mathrm{hr} \cdot \mathrm{wk}^{-1}\right)$ & $3.9 \pm 5.6$ & $3.9 \pm 4.4$ & 0.96 \\
\hline Triglycerides $\left(\mathrm{mg} \cdot \mathrm{dL}^{-1}\right)$ & $78.0 \pm 35.1$ & $85.5 \pm 24.1$ & 0.34 \\
\hline Cholesterol $\left(\mathrm{mg} \cdot \mathrm{dL}^{-1}\right)$ & $159.6 \pm 29.2$ & $166.9 \pm 42.2$ & 0.41 \\
\hline Glucose $\left(\mathrm{mg} \cdot \mathrm{dL}^{-1}\right)$ & $95.5 \pm 9.4$ & $95.7 \pm 6.0$ & 0.98 \\
\hline Malondialdehyde $\left(\mu \mathrm{mol} \cdot \mathrm{L}^{-1}\right)$ & $0.94 \pm 0.57$ & $1.01 \pm 0.46$ & 0.62 \\
\hline Advanced Oxidation Protein Products $\left(\mu \mathrm{mol} \cdot \mathrm{L}^{-1}\right)$ & $6.5 \pm 2.1$ & $6.2 \pm 1.7$ & 0.69 \\
\hline
\end{tabular}

No differences of statistical significance noted for any measured variable $(\mathrm{p}>0.05)$.

vitro exhibited increased ROS production with reduced levels of the intracellular antioxidant glutathione (GSH) [30]. Overwhelming of the intracellular oxidant buffering system appears to result from rampant mitochondrial ROS formation. These experiments were followed up in vivo by exposing rats to marijuana smoke and staining lung tissue. Rats exposed to marijuana smoke displayed a diminished mitochondrial membrane potential and decreased ATP levels [33]. Previous data indicates mitochondria with reduced respiratory chain activity and subsequent membrane potential are associated with increased ROS formation [35] though this seems to be the exception rather than the rule, as increased mitochondrial membrane potential is more often associated with increased ROS production [36]. Interestingly, micromolar concentrations of cannabinoids inhibit activity of respiratory chain complexes II, III, and IV [37]. It is important to note, more recent molecular work examines the effects of isolated cannabinoids rather than marijuana smoke as a whole.

In contrast to the above, cannabinoids have been reported to have antioxidant properties [29] [38] [39] [40] [41]. The principal cannabinoid constituents of marijuana smoke and the two cannabinoids garnering most of the scientific research are (-)-trans- $\Delta^{9}$-tetrahydrocannabinol (THC) and cannabidiol (CBD). CBD and THC have been demonstrated to attenuate ROS in a number of cell types [39] [40] [41] through both receptor-mediated [29] [38] and receptor-independent 
mechanisms [42]. Additionally, computational modeling suggests THC and CBD may have the potential to act as a free radical scavenger [43]. More importantly, cannabinoid receptors can be found either on the plasma or mitochondrial membranes [44] [45]. That said, molecular mechanisms and effects depend not only on the cannabinoid concentration but also the metabolic state of the cell and method used to induce oxidative stress though this still represents only a fraction of marijuana smoke.

In addition to the above, chronic exercise training has been show to increase antioxidant enzyme activity, which could help to offset any rise in ROS production [13] [14] [15]. As mentioned previously, cigarette smoke is a similar stimulus for producing ROS. In fact, exercised mice exposed to cigarette smoke experienced reduced oxidative damage to lipids and proteins compared to sedentary smoke-exposed counterparts [46]. Alternatively, postprandial oxidative stress is exacerbated in cigarette smokers [47]. In terms of lipid peroxidation, exercise appears to be an effective counter measure for postprandial oxidative stress in cigarette smokers [48]. Results presented here suggest a similar attenuation of oxidative stress markers in physically active marijuana smokers. Perhaps routine exercise can prove beneficial to protect against ROS production from marijuana smoking. Larger, longer term studies are needed to confirm this hypothesis, in particular involving a control group of inactive marijuana smokers.

Considering the above, it is not surprising given our subject sample that differences between the smokers and non-smokers were not apparent. Prior studies focused on marijuana smokers have noted increased oxidative stress markers in self-reported marijuana smokers. For instance, alveolar macrophages isolated from marijuana smokers displayed lower intracellular GSH levels [30]. Moreover, marijuana smokers reportedly exhibited increased levels of MDA with lower blood GSH and total antioxidant capacity, though this study made no mention of participant exercise status [34]. This discrepancy in our data from previously reported data is likely attributed to the beneficial adaptations to chronic exercise. In addition to protective effects of exercise against oxidative stress, it may protect cardio-metabolic parameters as well. Previous reports suggest marijuana smokers have increased systolic and diastolic blood pressure, with reduced high density lipoprotein-cholesterol (HDL-C) [49]. Regular participation in aerobic [50] and resistance [51] training can result in a lowering of SBP and DBP, which may suggest why blood pressure differences were not observed in our physically active marijuana smokers. Though we did not measure HDL-C, it would have been interesting to see if our active marijuana smokers had any reduction in HDL-C, considering the expected increase with regular exercise [52].

Related to the above findings, it is important to mention the limitations of our study. First, subjects were only required to have smoked marijuana for a minimum of three months prior to participating in this study. It is possible that long-term use of marijuana may have resulted in differing findings. Second, we only measured two commonly used biomarkers of oxidative stress and did so in 
blood samples. It is possible that different findings could have been observed if other biomarkers were included and/or if we had used other tissue (e.g., skeletal muscle). Third, since we did not provide the marijuana directly to subjects, it is possible that the potency of the plant varied from person to person and from use to use. Standardizing the use of marijuana may have improved the cleanliness of data. Fourth, while we included physical active subjects in this study, we did not have sedentary individuals acting as controls. This should be considered in future studies, as many marijuana smokers may be sedentary and this behavior may lead to differing results as compared to what was observed in the present study.

Clearly, the above limitations need to be considered, as the findings of the present study should not suggest that marijuana smoking can be done without harm. There exists multiple papers documenting the concerns of marijuana use, the first of which may be "marijuana use disorder" for which approximately 30\% of users meet criteria, as defined by the Diagnostic and Statistical Manual of Mental Disorders [4]. Moreover, users of marijuana, in particular heavy users, are more likely to have problems with use of alcohol and other drugs [53]. It has been demonstrated that acute marijuana smoking impairs driving performance [54], with an increase in motor vehicle fatalities linked to marijuana legalization [55]. Both short-term [56] and long-term [57] use can lead to cognitive performance decline. Individuals should consider these facts and utilize the data presented in this study only in the context of the "big picture".

\section{Conclusion}

In conclusion, our data indicate that within a sample of young, physically active men and women, regular marijuana smoking is not associated with an increase in select biomarkers of oxidative stress nor is it associated with an elevation in select markers of cardio-metabolic health. These findings in no way suggest that marijuana smoking can be done without harm, as multiple other outcomes needs to be considered prior to making a decision as to whether or not the use of marijuana may be justified.

\section{References}

[1] Schulenberg, J.E., Johnston, L.D., O'Malley, P.M., Bachman, J.G., Miech, R.A. and Patrick, M.E. (2017) Monitoring the Future National Survey Results on Drug Use, 1975-2016: Volume II, College Students and Adults Ages 19-55.

[2] Joffe, A. and Yancy, W.S. (2004) Legalization of Marijuana: Potential Impact on youth. Pediatrics, 113, e632-e638. https://doi.org/10.1542/peds.113.6.e632

[3] NIDA (2018) Marijuana. National Institute on Drug Abuse. https://www.drugabuse.gov/publications/research-reports/marijuana

[4] Hasin, D.S., Saha, T.D., Kerridge, B.T., Goldstein, R.B., Chou, S.P., Zhang, H., Jung, J., Pickering, R.P., Ruan, W.J. and Smith, S.M. (2015) Prevalence of Marijuana Use Disorders in the United States between 2001-2002 and 2012-2013. JAMA Psychiatry, 72, 1235-1242. https://doi.org/10.1001/jamapsychiatry.2015.1858 
[5] Jacob, J.A. (2015) Marijuana Use Has Doubled among Us Adults. JAMA, 314, 2607-2607. https://doi.org/10.1001/jama.2015.17171

[6] Kerr, D.C., Bae, H., Phibbs, S. and Kern, A.C. (2017) Changes in Undergraduates' Marijuana, Heavy Alcohol, and Cigarette Use Following Legalization of Recreational Marijuana Use in Oregon. Addiction. https://doi.org/10.1111/add.13906

[7] Baron, E.P. (2015) Comprehensive Review of Medicinal Marijuana, Cannabinoids, and Therapeutic Implications in Medicine and Headache: What a Long Strange Trip It's Been... Headache: The Journal of Head and Face Pain, 55, 885-916. https://doi.org/10.1111/head.12570

[8] Larsen, D. (2009) Pot-Smoking Phelps Isn't Alone among Athletes. Forbes Magazine.

https://www.forbes.com/2009/02/04/michael-phelps-marijuana-opinions-contribut ors_0204_dana_larsen.html

[9] Nuñez, A. (2017) The First Weed Gym Will Open up in California. Men's Health.

[10] Barbieri, E., Agostini, D., Polidori, E., Potenza, L., Guescini, M., Lucertini, F., Annibalini, G., Stocchi, L., De Santi, M. and Stocchi, V. (2015) The Pleiotropic Effect of Physical Exercise on Mitochondrial Dynamics in Aging Skeletal Muscle. Oxidative Medicine and Cellular Longevity, 2015, Article ID: 917085.

[11] Diamond, A. (2015) Effects of Physical Exercise on Executive Functions: Going beyond Simply Moving to Moving with Thought. Annals of Sports Medicine and Research, 2, 1011.

[12] Wilson, M.G., Ellison, G.M. and Cable, N.T. (2016) Basic Science behind the Cardiovascular Benefits of Exercise. British Journal of Sports Medicine, 50, 93-99. https://doi.org/10.1136/bjsports-2014-306596rep

[13] de Sousa, C.V., Sales, M.M., Rosa, T.S., Lewis, J.E., de Andrade, R.V. and Simões, H.G. (2017) The Antioxidant Effect of Exercise: A Systematic Review and Meta-Analysis. Sports Medicine, 47, 277-293. https://doi.org/10.1007/s40279-016-0566-1

[14] Radak, Z., Zhao, Z., Koltai, E., Ohno, H. and Atalay, M. (2013) Oxygen Consumption and Usage during Physical Exercise: The Balance between Oxidative Stress and Ros-Dependent Adaptive Signaling. Antioxidants \& Redox Signaling, 18, 1208-1246.

[15] Siu, P.M., Pei, X.M., Teng, B.T., Benzie, I.F., Ying, M. and Wong, S.H. (2011) Habitual Exercise Increases Resistance of lymphocytes to Oxidant-Induced DNA Damage by Upregulating Expression of Antioxidant and DNA Repairing Enzymes. $E_{X}$ perimental Physiology, 96, 889-906. https://doi.org/10.1113/expphysiol.2011.058396

[16] Ott, M., Gogvadze, V., Orrenius, S. and Zhivotovsky, B. (2007) Mitochondria, Oxidative Stress and Cell Death. Apoptosis, 12, 913-922. https://doi.org/10.1007/s10495-007-0756-2

[17] Ryter, S.W., Kim, H.P., Hoetzel, A., Park, J.W., Nakahira, K., Wang, X. and Choi, A.M. (2007) Mechanisms of Cell Death in Oxidative Stress. Antioxidants \& Redox Signaling, 9, 49-89.

[18] Toyokuni, S., Okamoto, K., Yodoi, J. and Hiai, H. (1995) Persistent Oxidative Stress in Cancer. FEBS Letters, 358, 1-3. https://doi.org/10.1016/0014-5793(94)01368-B

[19] Valko, M., Rhodes, C., Moncol, J., Izakovic, M. and Mazur, M. (2006) Free Radicals, Metals and Antioxidants in Oxidative Stress-Induced Cancer. Chemico-Biological Interactions, 160, 1-40. https://doi.org/10.1016/j.cbi.2005.12.009

[20] Emerit, J., Edeas, M. and Bricaire, F. (2004) Neurodegenerative Diseases and Oxida- 
tive Stress. Biomedicine \& Pharmacotherapy, 58, 39-46.

https://doi.org/10.1016/j.biopha.2003.11.004

[21] Uttara, B., Singh, A.V., Zamboni, P. and Mahajan, R. (2009) Oxidative Stress and Neurodegenerative Diseases: A Review of Upstream and Downstream Antioxidant Therapeutic Options. Current Neuropharmacology, 7, 65-74. https://doi.org/10.2174/157015909787602823

[22] Lakshmi, S.V., Padmaja, G., Kuppusamy, P. and Kutala, V.K. (2009) Oxidative Stress in Cardiovascular Disease. Indian Journal of Biochemistry \& Biophysics, 46, 421-440.

[23] Schnabel, R. and Blankenberg, S. (2007) Oxidative Stress in Cardiovascular Disease: Successful Translation from Bench to Bedside? Circulation, 116, 1338-1340.

[24] Maritim, A., Sanders, A. and Watkins, J. (2003) Diabetes, Oxidative Stress, and Antioxidants: A Review. Journal of Biochemical and Molecular Toxicology, 17, 24-38. https://doi.org/10.1002/jbt.10058

[25] Halliwell, B.B. and Poulsen, H.E. (2006) Cigarette Smoke and Oxidative Stress. Springer, Berlin. https://doi.org/10.1007/3-540-32232-9

[26] Isik, B., Ceylan, A. and Isik, R. (2007) Oxidative Stress in Smokers and Non-Smokers. Inhalation Toxicology, 19, 767-769. https://doi.org/10.1080/08958370701401418

[27] Van der Vaart, H., Postma, D., Timens, W. and Ten Hacken, N. (2004) Acute Effects of Cigarette Smoke on Inflammation and Oxidative Stress: A Review. Thorax, 59, 713-721. https://doi.org/10.1136/thx.2003.012468

[28] Atakan, Z. (2012) Cannabis, a Complex Plant: Different Compounds and Different Effects on Individuals. Therapeutic Advances in Psychopharmacology, 2, 241-254. https://doi.org/10.1177/2045125312457586

[29] Hampson, A., Grimaldi, M., Axelrod, J. and Wink, D. (1998) Cannabidiol and (-) 8 -Tetrahydrocannabinol Are Neuroprotective Antioxidants. Proceedings of the National Academy of Sciences of the United States of America, 95, 8268-8273. https://doi.org/10.1073/pnas.95.14.8268

[30] Sarafian, T.A., Magallanes, J.A.M., Shau, H., Tashkin, D. and Roth, M.D. (1999) Oxidative Stress Produced by Marijuana Smoke: An Adverse Effect Enhanced by Cannabinoids. American Journal of Respiratory Cell and Molecular Biology, 20, 1286-1293. https://doi.org/10.1165/ajrcmb.20.6.3424

[31] Jentzsch, A.M., Bachmann, H., Fürst, P. and Biesalski, H.K. (1996) Improved Analysis of Malondialdehyde in Human Body Fluids. Free Radical Biology \& Medicine, 20, 251-256. https://doi.org/10.1016/0891-5849(95)02043-8

[32] Witko-Sarsat, V., Friedlander, M., Capeillère-Blandin, C., Nguyen-Khoa, T., Nguyen, A.T., Zingraff, J., Jungers, P. and Descamps-Latscha, B. (1996) Advanced Oxidation Protein Products as a Novel Marker of Oxidative Stress in Uremia. Kidney International, 49, 1304-1313. https://doi.org/10.1038/ki.1996.186

[33] Sarafian, T.A., Habib, N., Oldham, M., Seeram, N., Lee, R.-P., Lin, L., Tashkin, D.P. and Roth, M.D. (2006) Inhaled Marijuana Smoke Disrupts Mitochondrial Energetics in Pulmonary Epithelial Cells in Vivo. American Journal of Physiology-Lung Cellular and Molecular Physiology, 290, L1202-L1209.

https://doi.org/10.1152/ajplung.00371.2005

[34] Toson, E.A. (2011) Impact of Marijuana Smoking on Liver and Sex Hormones: Correlation with Oxidative Stress. Nature and Science, 9, 76-87.

[35] Lebiedzinska, M., Karkucinska-Wieckowska, A., Giorgi, C., Karczmarewicz, E., Pronicka, E., Pinton, P., Duszynski, J., Pronicki, M. and Wieckowski, M.R. (2010) Oxidative Stress-Dependent p66shc Phosphorylation in Skin Fibroblasts of Children 
with Mitochondrial Disorders. Biochimica et Biophysica Acta (BBA)-Bioenergetics, 1797, 952-960.

[36] Suski, J.M., Lebiedzinska, M., Bonora, M., Pinton, P., Duszynski, J. and Wieckowski, M.R. (2012) Relation between Mitochondrial Membrane Potential and ROS Formation. In: Carlos, M. and PalmeiraAntónio, J., Eds., Moreno Mitochondrial Bioenergetics, Springer, Berlin, 183-205.

https://doi.org/10.1007/978-1-61779-382-0_12

[37] Singh, N., Hroudová, J. and Fišar, Z. (2015) Cannabinoid-Induced Changes in the Activity of Electron Transport Chain Complexes of Brain Mitochondria. Journal of Molecular Neuroscience, 56, 926-931. https://doi.org/10.1007/s12031-015-0545-2

[38] Hampson, A.J., Grimaldi, M., Lolic, M., Wink, D., Rosenthal, R. and Axelrod, J. (2000) Neuroprotective Antioxidants from Marijuana. Annals of the New York Academy of Sciences, 899, 274-282. https://doi.org/10.1111/j.1749-6632.2000.tb06193.x

[39] Mukhopadhyay, P., Rajesh, M., Horváth, B., Bátkai, S., Park, O., Tanchian, G., Gao, R.Y., Patel, V., Wink, D.A. and Liaudet, L. (2011) Cannabidiol Protects against Hepatic Ischemia/Reperfusion Injury by Attenuating Inflammatory Signaling and Response, Oxidative/Nitrative Stress, and Cell Death. Free Radical Biology \& Medicine, 50, 1368-1381. https://doi.org/10.1016/j.freeradbiomed.2011.02.021

[40] Pan, H., Mukhopadhyay, P., Rajesh, M., Patel, V., Mukhopadhyay, B., Gao, B., Haskó, G. and Pacher, P. (2009) Cannabidiol Attenuates Cisplatin-Induced Nephrotoxicity by Decreasing Oxidative/Nitrosative Stress, Inflammation, and Cell Death. Journal of Pharmacology and Experimental Therapeutics, 328, 708-714. https://doi.org/10.1124/jpet.108.147181

[41] Rajesh, M., Mukhopadhyay, P., Bátkai, S., Patel, V., Saito, K., Matsumoto, S., Kashiwaya, Y., Horváth, B., Mukhopadhyay, B. and Becker, L. (2010) Cannabidiol Attenuates Cardiac Dysfunction, Oxidative Stress, Fibrosis, and Inflammatory and Cell Death Signaling Pathways in Diabetic Cardiomyopathy. Journal of the American College of Cardiology, 56, 2115-2125. https://doi.org/10.1016/j.jacc.2010.07.033

[42] Chen, Y. and Buck, J. (2000) Cannabinoids Protect Cells from Oxidative Cell Death: A Receptor-Independent Mechanism. Journal of Pharmacology and Experimental Therapeutics, 293, 807-812.

[43] Borges, R.S., Batista, J., Viana, R.B., Baetas, A.C., Orestes, E., Andrade, M.A., Honório, K.M. and da Silva, A.B. (2013) Understanding the Molecular Aspects of Tetrahydrocannabinol and Cannabidiol as Antioxidants. Molecules, 18, 12663-12674. https://doi.org/10.3390/molecules181012663

[44] Hebert-Chatelain, E., Reguero, L., Puente, N., Lutz, B., Chaouloff, F., Rossignol, R., Piazza, P.-V., Benard, G., Grandes, P. and Marsicano, G. (2014) Cannabinoid Control of Brain Bioenergetics: Exploring the Subcellular Localization of the CB1 Receptor. Molecular Metabolism, 3, 495-504. https://doi.org/10.1016/j.molmet.2014.03.007

[45] Zou, S. and Kumar, U. (2018) Cannabinoid Receptors and the Endocannabinoid System: Signaling and Function in the Central Nervous System. International Journal of Molecular Sciences, 19, 833. https://doi.org/10.3390/ijms19030833

[46] Nesi, R.T., de Souza, P.S., dos Santos, G.P., Thirupathi, A., Menegali, B.T., Silveira, P.C.L., da Silva, L.A., Valença, S.S. and Pinho, R.A. (2016) Physical Exercise Is Effective in Preventing Cigarette Smoke-Induced Pulmonary Oxidative Response in Mice. International Journal of Chronic Obstructive Pulmonary Disease, 11, 603-610. https://doi.org/10.2147/COPD.S93958 
[47] Bloomer, R.J., Solis, A.D., Fisher-Wellman, K.H. and Smith, W.A. (2008) Postprandial Oxidative Stress Is Exacerbated in Cigarette Smokers. British Journal of Nutrition, 99, 1055-1060. https://doi.org/10.1017/S0007114507844370

[48] Bloomer, R.J. and Fisher-Wellman, K.H. (2009) Postprandial Oxidative Stress in Exercise Trained and Sedentary Cigarette Smokers. International Journal of Environmental Research and Public Health, 6, 579-591. https://doi.org/10.3390/ijerph6020579

[49] Muniyappa, R., Sable, S., Ouwerkerk, R., Mari, A., Gharib, A.M., Walter, M., Courville, A., Hall, G., Chen, K.Y. and Volkow, N.D. (2013) Metabolic Effects of Chronic Cannabis Smoking. Diabetes Care, 36, 2415-2422. https://doi.org/10.2337/dc12-2303

[50] Kelley, G.A., Kelley, K.A. and Vu Tran, Z. (2001) Aerobic Exercise and Resting Blood Pressure: A Meta-Analytic Review of Randomized, Controlled Trials. Preventive Cardiology, 4, 73-80. https://doi.org/10.1111/j.1520-037X.2001.00529.x

[51] Cornelissen, V.A., Fagard, R.H., Coeckelberghs, E. and Vanhees, L. (2011) Impact of Resistance Training on Blood Pressure and Other Cardiovascular Risk Factors: A Meta-Analysis of Randomized, Controlled Trials. Hypertension, 58, 950-958.

[52] Couillard, C., Després, J.-P., Lamarche, B., Bergeron, J., Gagnon, J., Leon, A.S., Rao, D., Skinner, J.S., Wilmore, J.H. and Bouchard, C. (2001) Effects of Endurance Exercise Training on Plasma HDL Cholesterol Levels Depend on Levels of Triglycerides: Evidence from Men of the Health, Risk Factors, Exercise Training and Genetics (Heritage) Family Study. Arteriosclerosis, Thrombosis, and Vascular Biology, 21, 1226-1232. https://doi.org/10.1161/hq0701.092137

[53] Choi, N.G., Di Nitto, D.M. and Marti, C.N. (2018) A Longitudinal Assessment of Change in Marijuana Use with Other Substance Use Problems. The American Journal of Drug and Alcohol Abuse, 1-11. https://doi.org/10.1080/00952990.2018.1461879

[54] Micallef, J., Dupouey, J., Jouve, E., Truillet, R., Lacarelle, B., Taillard, J., Daurat, A., Authié, C., Blin, O. and Rascol, O. (2018) Cannabis Smoking Impairs Driving Performance on Simulator and Real Driving: A Randomized, Double Blind, Placebo-Controlled, Crossover Trial. Fundamental \& Clinical Pharmacology. https://doi.org/10.1111/fcp.12382

[55] Steinemann, S., Galanis, D., Nguyen, T. and Biffl, W. (2018) Motor Vehicle Crash Fatalaties and Undercompensated Care Associated with Legalization of Marijuana. The Journal of Trauma and Acute Care Surgery. https://doi.org/10.1097/TA.0000000000001983

[56] Dager, A.D., Tice, M.R., Book, G.A., Tennen, H., Raskin, S.A., Austad, C.S., Wood, R.M., Fallahi, C.R., Hawkins, K.A. and Pearlson, G.D. (2018) Relationship between fmri Response during a Nonverbal Memory Task and Marijuana Use in College Students. Drug and Alcohol Dependence, 188, 71-78.

https://doi.org/10.1016/j.drugalcdep.2018.03.025

[57] Lovell, M., Bruno, R., Johnston, J., Matthews, A., McGregor, I., Allsop, D. and Lintzeris, N. (2018) Cognitive, Physical, and Mental Health Outcomes between LongTerm Cannabis and Tobacco Users. Addictive Behaviors, 79, 178-188. https://doi.org/10.1016/j.addbeh.2017.12.009 